\title{
Semut Subfamili Myrmicinae di Suaka Alam Maninjau Utara Selatan, Kabupaten Agam, Sumatera Barat
}

\section{Ant subfamily Myrmicinae at Maninjau Utara Selatan Nature Reserve, Agam District, West Sumatra}

\author{
Susan Septriani*), Henny Herwina dan Mairawita
}

Laboratorium Riset Taksonomi Hewan, Jurusan Biologi, FMIPA Universitas Andalas, Limau Manis Padang 25163

${ }^{*}$ Koresponden: susan1110422008@gmail.com

\begin{abstract}
Research about inventory of ants Myrmicinae (Hymenoptera: Formicidae) in Nature Reserve Maninjau Utara-Selatan, Agam, West Sumatra was conducted from June to December 2015 by using the "Quadra protocol" which consist of a combination of four methods: free collection, leaf litter sampling, soil sampling, honey bait. A total of 19 species, 9 genera, 5 tribe were collected. Pheidole was found as genus with the highest number of species (9 species), followed by Crematogaster (3 species).
\end{abstract}

Keywords: Ants, Myrmicinae, Quadra protocol, Maninjau Nature Reserve

\section{Pendahuluan}

Semut merupakan kelompok serangga yang memiliki peranan penting dalam ekosistem (Kaspari, 2000) diantaranya berasosiasi dengan organisme lain, menjadi predator dan pemangsa (Schultz dan McGlynn, 2000; Folgarait, 1998). Selain berperan dalam ekologi, keberadaan semut di suatu area dapat digunakan sebagai biomonitoring konservasi dan pengelolaan kawasan (Agosti et al., 2000). Semut adalah kelompok serangga sosial dan memiliki jumlah yang berlimpah (Hansen dan Art, 2011). Keberadaannya yang banyak dan penyebarannya yang sangat luas menyebabkan semut dapat ditemukan di habitat darat dengan jumlah individu yang melebihi kebanyakan hewan-hewan di darat lainnya (Borror et al., 2005). Salah satu dari subfamili semut yang memiliki jumlah dan penyebaran yang luas adalah subfamili Myrmicinae.

Menurut Eguchi (2001), Myrmicinae merupakan subfamili semut yang memiliki jumlah genera yang paling banyak, lebih dari
900 spesies di dunia yang telah dideskripsikan. Subfamili Myrmicinae tersebar di seluruh dunia baik di daerah tropis, subtropis maupun daerah temprate.

Suaka Alam Maninjau Utara Selatan merupakan kawasan hutan yang secara administratif terletak di Kabupaten Agam dengan luas \pm 22.106 Ha. Kawasan hutan ini sebagian tumbuh di bukit-bukit yang curam yang mengelilingi danau Maninjau (BKSDA, 2007). Jenis-jenis tumbuhan di Kawasan Suaka Alam Maninjau Utara Selatan didominasi oleh jenis-jenis seperti surian (Tonna sureni), bayur (Pterospermum javanicum) dan medang (Litsea spp) (Munawaroh, 2009). Selain itu kawasan ini memiliki keanekaragaman yang tinggi baik itu flora maupun faunanya yang belum terungkap dan belum pernah dilaporkan salah satu diantaranya adalah semut. Oleh karena itu, hal ini menjadi suatu kajian yang menarik untuk dibahas dan dikaji lebih jauh. 


\section{Metode Penelitian}

Penelitian ini dilakukan di Suaka Alam Maninjau Utara Selatan, Kabupaten Agam, Sumatera Barat. Pengambilan sampel dilakukan dengan mengikuti standar pengumpulan semut "Quadra Protocol" dengan menggunakan kombinasi empat metode yaitu Hand collection (HC), Leaf litter sifting (LLS), Soil sampling (SS), Honey bait (HB) (Hashimoto, Yamane dan Mohamed, 2001). Penelitian ini dilakukan di dua lokasi yaitu di pinggir hutan dan di dalam hutan, dimana pada masing-masing lokasi dibuat satu transek sepanjang $180 \mathrm{~m}$ yang dibagi menjadi 3 subtransek, masing-masing subtransek berukuran 60 meter.

Beberapa parameter yang diukur mengacu kepada Eguchi (2000): Panjang Total (PT), Lebar Kepala (LK), Panjang Kepala (PK), Panjang Scape (PS), Panjang Alitrunk (PA), Panjang Femur (PF). Pengidentifikasian diupayakan sampai tingkat spesies demgan menggunakan buku panduan: (Bolton, 1994; Hashimoto, 2003 dan Jaitrong, 2011). Sampel yang hanya teridentifikasi sampai genus diberi kode dibelakang genus sesuai collector (SKY: collector adalah Seiki Yamane, Kagoshima University dan HH: collector adalah Henny Herwina, Universitas Andalas).

\section{Hasil dan Pembahasan}

Berdasarkan penelitian yang telah dilakukan mengenai jenis-jenis semut Subfamili Myrmicinae di Kawasan Suaka Alam Maninjau Utara-Selatan, Kabupaten Agam Sumatera Barat didapatkan 19 jenis, 5 tribe, 9 genera, dan 1.824 individu (Tabel 1). Pheidole merupakan genus yang paling banyak didapatkan yaitu sebanyak 9 jenis, diikuti oleh genus Crematogaster sebanyak 3 jenis. Menurut Eguchi (2000), genus Pheidole merupakan kelompok yang memiliki jenis yang beragam di dunia. Pada kawasan Indo-Malaya terdapat 52 spesies dari genus Pheidole. Wilson (2005) menyatakan bahwa Pheidole adalah kelompok yang dominan di dunia.

Hilmi, Herwina dan Dahelmi (2015) di Cagar Alam Rimbo Panti, Sumatera Barat menemukan 25 jenis semut yang tergolong ke dalam subfamily Myrmicinae, dimana Pheidole juga merupakan genus yang paling banyak didapatkan jenisnya (11 jenis). Jumlah jenis yang didapatkan pada kawasan ini lebih sedikit dibandingkan dengan yang ditemukan Hilmi et al., (2015). Hal ini diduga karena adanya perbedaan lokasi, pengaruh dari keadaan lingkungan seperti keragaman jenis tumbuhan, suhu dan kelembaban.

Jenis semut yang didapatkan ini bisa ditemukan di pohon, ranting kayu, di bawah batu, serasah, ditumpukan kayu lapuk, dan di saranngnya dengan metoda hand collecting, honey bait trap, soil core sampling dan leaf litter sifting, pada dua tipe area (pinggir dan dalam hutan). Deskripsi dari setiap jenis yang didapatkan adalah sebagai berikut:

Tribe Attini, Genus Pheidole Westwood, 1839. Karakteristik dari genus Pheidole adalah antenna terdiri dari 12 segmen termasuk scape; tiga segmen pada ujung antenna berukuran lebih besar (segmen club); mandibula dengan tipe triangularis; thorak dilihat dari bagian lateral, sisi dorsal dari propodeum lebih rendah dari pronotum (mengalami penyempitan pada bagian mesonotum); propodeum memiliki sepasang duri; petiole mempunyai dua nodus; genus ini pada umumnya bersifat dimorphisme dimana minor dan major worker dapat dibedakan dengan jelas (Hashimoto, 2003).

Pheidole aristoteles Forel, 1911. Deskripsi dari jenis ini adalah memiliki mandibula dengan tipe triangularis; mata kecil; frontal carinae lurus; sisi dorsal pronotum berbentuk cembung dan permukaannya licin; sisi dorsal mesonotum sedikit cembung; propodeum cembung dan memiliki duri; gaster berbentuk oval; tubuh ditutupi oleh rambut-rambut halus yang panjang; petiole lebih kecil daripada postpetiole; tubuh berwarna kuning kecoklatan. Pengukuran parameter tubuh 
$(\mathrm{n}=6)$; panjang tubuh 2,00-2,20 $\mathrm{mm}$; lebar

$0,70 \mathrm{~mm}($ Gambar 1, A).

kepala $0,50-0,50 \mathrm{~mm}$; panjang alitrunk 0,60-

Tabel 1. Subfamili Myrmicinae, Tribe, Jenis dan jumlah individu semut yang didapatkan di Suaka Alam Maninjau Utara Selatan, Kabupaten Agam, Sumatera Barat.

\begin{tabular}{|c|c|c|}
\hline \multirow[b]{2}{*}{ No. } & \multicolumn{2}{|l|}{ Subfamili } \\
\hline & $\begin{array}{l}\text { Tribe } \\
\text { Jenis }\end{array}$ & Total \\
\hline & \multicolumn{2}{|l|}{ Myrmicinae } \\
\hline & \multicolumn{2}{|l|}{ Attini } \\
\hline 1. & Pheidole aristoteles Forel, 1911 & 6 \\
\hline 2. & Pheidole longipes (Latreille, 1802) & 882 \\
\hline 3. & Pheidole quadrensis (Forel, 1900) & 1 \\
\hline 4. & Pheidole sp. 1 of $\mathrm{HH}$ & 16 \\
\hline 5. & Pheidole sp. 3 of $\mathrm{HH}$ & 4 \\
\hline 6. & Pheidole sp. 5 of $\mathrm{HH}$ & 5 \\
\hline 7. & Pheidole sp. 12 of $\mathrm{HH}$ & 314 \\
\hline 8. & Pheidole sp. 17 of HH (Mayor) & 3 \\
\hline 9. & Pheidole sp. 18 of $\mathrm{HH}$ & 1 \\
\hline \multirow[t]{2}{*}{10.} & Strumygenis sp. 2 of $\mathrm{HH}$ & 2 \\
\hline & \multicolumn{2}{|l|}{ Crematogastrini } \\
\hline 11. & Acanthomyrmex ferox Emery, 1893 & 50 \\
\hline 12. & $\begin{array}{l}\text { Crematogaster } \quad \text { (Decacrema) } \text { borneensis } \\
\text { Andre, } 1896\end{array}$ & 8 \\
\hline 13. & $\begin{array}{l}\text { Crematogaster(Orthocrema) longipilosa } \\
\text { Forel, } 1907\end{array}$ & 8 \\
\hline 14. & $\begin{array}{l}\text { Crematogaster } \\
\text { Emery, } 1990\end{array}$ & 16 \\
\hline 15. & Pheidogleton sileneus Smith, 1858 & 149 \\
\hline \multirow[t]{2}{*}{16.} & Tetramorium pacificum Mayr, 1870 & 1 \\
\hline & Pheidolini & \\
\hline \multirow[t]{2}{*}{17.} & Lophomyrmex bedoti Emery, 1893 & 11 \\
\hline & Solenopsidini & \\
\hline \multirow[t]{2}{*}{18.} & Myrmicaria sp. of $\mathrm{HH}$ & 344 \\
\hline & Stenammini & \\
\hline \multirow[t]{4}{*}{19.} & $\begin{array}{llll}\text { Aphaenogaster } & \text { (Deromyrma) } & c f . & \text { feae } \\
\text { Emery, } 1889 & & & \\
\end{array}$ & 3 \\
\hline & Total Individu & 1824 \\
\hline & Total Jenis & 19 \\
\hline & Total Genus & 9 \\
\hline
\end{tabular}

Pheidole longipes (Latreille, 1802). Deskripsi dari jenis ini adalah kepala berbentuk oval; antenna terdiri dari 12 segmen termasuk scape; mandibula memiliki tipe triangularis; mata terletak dibagian pinggir atas kepala; kepala dan thoraks jelas terpisah; sisi dorsal dari pronotum cembung; sisi dorsal dari mesonotum cekung; propodeum memiliki sepasang duri yang pendek; petiole lebih panjang daripada pospetiole; permukaan kepala dan pronotum mengkilap; kepala dan gaster memiliki bulu-bulu halus yang jarang; femur, tibia dan tarsus ditutupi oleh bulu-bulu halus yang banyak. Pengukuran parameter tubuh $(\mathrm{n}=10)$; panjang tubuh $5,00-5,00 \mathrm{~mm}$; lebar kepala 0,90-1,00 mm; panjang alitrunk 1,80-2,00 mm (Gambar 1, B). 
Pheidole quadrensis (Forel, 1900). Deskripsi dari jenis ini adalah mandibula triangularis; sisi dorsal pronotum cembung; pronotum memiliki sepasang duri yang panjang; propodeum memiliki sepasang duri yang lebih pendek dari pronotum; petiole dengan dua nodus yang jelas; memiliki peduncle; petiole membulat pada bagian atas; postpetiole berukuran lebih besar dibandingkan petiole; permukaan kepala, mesosoma dan petiole tidak licin dan mengkilap seperti gaster; tubuh ditutupi oleh bulu-bulu halus; seluruh tubuh berwarna coklat kemerahan. Pengukuran parameter tubuh $(\mathrm{n}=1)$; panjang tubuh $3,00 \mathrm{~mm}$; lebar kepala $1,80 \mathrm{~mm}$; panjang alitrunk $1,80 \mathrm{~mm}$ (Gambar 1, C).

Pheidole sp. 1 of HH. Deskripsi dari jenis ini adalah kepala berbentuk persegi dan pipih bila dilihat dari arah lateral; mata kecil yang terletak di bagian pinggir tengah kepala; tidak memiliki antennal scrobe; antenna terdiri dari 12 segmen; memiliki antennal socket; thorak dilihat dari bagian lateral, sisi dorsal dari pronotum dan mesonotum cembung; propodeum memiliki duri; petiole lebih lebar dibandingkan post petiole; permukaan kepala licin dan berwarna coklat; tubuh ditutupi oleh bulu-bulu yang halus. Pengukuran parameter tubuh $(\mathrm{n}=10)$; panjang tubuh 2,00-2,20 mm; lebar kepala 0,50-0,60 $\mathrm{mm}$; panjang alitrunk 0,60-0,70 mm (Gambar $1, \mathrm{D})$.

Pheidole sp. 3 of HH. Deskripsi dari jenis ini adalah kepala berbentuk oval; scape lebih panjang dari kepala; memiliki tiga segmen club; tipe mandibula berbentuk triangular; pada propodeum terdapat duri; petiole dengan tipe squamiform; petiole memiliki ukuran yang kecil dibandingkan postpetiole; gaster membulat dan ditutupi oleh bulu-bulu halus; tubuh berwarna coklat kemerahan. Pengukuran parameter tubuh $(\mathrm{n}=4)$; panjang tubuh 3,50-4,40 $\mathrm{mm}$; lebar kepala 0,90-1,00 mm; panjang alitrunk 1,101,40 mm (Gambar 1, E).

Pheidole sp. 5 of HH. Deskripsi dari jenis ini adalah kepala berbentuk oval pipih; mata kecil terdapat di bagian pinggir tengah kepala; mandibula dengan tipe triangularis; memiliki antennal socket; sisi dorsal pronotum lebih cembung dibandingkan bagian mesonotum; propodeum memiliki sepasang duri; petiole dengan dua nodus yang jelas; permukaan kepala, pronotum, petiole dan gaster licin dan mengkilap; mesonotum dan propodeum sedikit kasar dengan bintikbintik kecil; tubuh ditutupi oleh bulu-bulu halus yang jarang. Pengukuran parameter tubuh $(\mathrm{n}=5)$; panjang tubuh $1,50-2,00 \mathrm{~mm}$; lebar kepala $0,50 \mathrm{~mm}$; panjang alitrunk 0,60 $0,80 \mathrm{~mm}$ (Gambar 1, G).

Pheidole sp. 12 of HH. Deskripsi dari jenis ini adalah mandibula triangularis; tidak memiliki antennal socket; memiliki clypeus dan frontal carinae lurus; sisi dorsal dan mesonotum cembung; propodeum cembung tetapi lebih kecil dibandingkan pronotum; propodeum memiliki sepasang duri yang kecil; petiole dengan dua nodus yang terpisah jelas; petiole lebih kecil dibandingkan dengan postpetiole; permukaan tubuh licin dan mengkilap serta ditutupi oleh bulu-bulu halus; kepala, thorak berwarna kuning; gaster berwarna kuning kehitaman. Pengukuran parameter tubuh $(\mathrm{n}=10)$; panjang tubuh 2,50 3,00 mm; lebar kepala 0,50-0,70 mm; panjang alitrunk 0,70-1,00 mm (Gambar 1, F).

Pheidole sp. 17 of HH. Deskripsi dari jenis ini adalah memiliki mata kecil; memiliki antennal socket; frontal carinae melebar kesamping; sisi dorsal pronotum cembung; mesonotum terlihat menyatu dengan propodeum; propodeum memiliki sepasang duri; gaster berbentuk oval; petiole membulat keatas; permukaan tubuh ditutupi oleh bulubulu halus. Pengukuran parameter tubuh $(\mathrm{n}=3)$; panjang tubuh 2,00-2,20 mm; lebar kepala 0,80-0,80 mm; panjang alitrunk 0,600,70 mm (Gambar 1, H).

Pheidole sp. 18 of HH. Deskripsi dari jenis ini adalah mandibula dengan tipe triangularis; memiliki antennal socket dan clypeus; antennal scrobe tidak terlihat jelas; sisi dorsal pronotum dan mesonotum cembung; propodeum cembung, lebih kecil dibandingkan dengan pronotum; propodeum 
memiliki sepasang duri yang panjang; petiole dengan dua nodus yang jelas; petiole berukuran kecil dibanding postpetiole; post petiole berbentuk bulat; memiliki peduncle yang panjang; permukaan kepala, petiole dan gaster licin dan mengkilap; bagian mesosoma agak kasar; tubuh berwarna coklat kehitaman. Pengukuran parameter tubuh $(\mathrm{n}=1)$; panjang tubuh 2,80 mm; lebar kepala 1,60 $\mathrm{mm}$; panjang alitrunk 1,20 $\mathrm{mm}$ (Gambar 1, I).

Genus Strumygenis Smith, 1860. Karakteristik dari genus Strumygenis adalah kepala berbentuk segitiga atau hati; antenna pendek terdiri dari 4-6 segmen; dua segmen pada bagian ujung antenna berukuran lebih besar; memiliki rahang panjang dan melengkung; terdapat duri pada bagian propodeum; petiole mempunyai dua nodus (Hashimoto, 2003).

Strumygenis sp. 2 of HH. Deskripsi dari jenis ini adalah kepala berbentuk segitiga (triangular) pipih; mandibula panjang dan menyempit; propodeum memiliki sepasang duri yang kecil; mesonotum terlihat menyatu dengan pronotum; scape lebih pendek dari kepala; mempunyai dua nodus petiole yang berbentuk bulat; tubuh berwarna coklat keemasan; tubuh ditutupi oleh makro setae yang jarang. Pengukuran parameter tubuh $(\mathrm{n}=2)$; panjang tubuh 2,00-3,00 $\mathrm{mm}$; lebar kepala 0,50-0,80 mm; panjang alitrunk 0,701,00 mm (Gambar 1, J).

Genus Acanthomyrmex Emery, 1893. Karakteristik dari genus Acanthomyrmex adalah antenna terdiri dari 12 segmen; bentuk mandibula triangularis; memiliki 2 nodus (petiole dan postpetiole); terdapat sepasang duri pada bagian mesonotum yang berukuran pendek; propodeum dan pronotum memiliki satu pasang duri (Bolton, 1994) dan (Hashimoto 2003).

Tribe Crematogastrini,

Acanthomyrmex ferox Emery, 1893. Deskripsi dari jenis adalah antenna terdiri dari 12 segmen; tipe mandibula berbentuk triangularis; pronotum dan propodeum memiliki sepasang duri yang panjang; memiliki 2 nodus (petiole dan postpetiole), bagian petiole memiliki sepasang duri; permukaan tubuh kasar dengan pola berlubang; permukaan gaster licin; mata terletak dibagian pinggir tengah kepala; kepala dan mesosoma memiliki warna merah kecoklatan; gaster memiliki warna coklat. Pengukuran parameter tubuh $(\mathrm{n}=10)$; panjang tubuh 4,00-4,10 mm; lebar kepala 1,00-1,10 $\mathrm{mm}$; panjang alitrunk 1,10-1,20 mm (Gambar 2, K).

Genus Crematogaster Lund, 1831. Karakteristik dari genus Crematogaster adalah memiliki antenna 10-11 segmen; terdapat sepasang duri pada propodeum; memiliki dua nodus yaitu petiole dan postpetiole dimana postpetiole berada pada permukaan atas dari gaster; bagian ujung gaster meruncing (Hashimoto, 2003).

\section{Crematogaster}

(Decacrema)

borneensis Andre, 1896. Deskripsi dari jenis ini adalah kepala bulat; tidak memiliki antennal scrobe; memiliki antennal socket; pronotum dan mesonotum cembung dilihat dari arah lateral; propodeum memiliki duri yang kecil; postpetiole bersambung dengan gaster segmen pertama; gaster memanjang dan memiliki sting; tubuh ditutupi oleh bulubulu halus; seluruh tubuh berwarna coklat kehitaman. Pengukuran parameter tubuh $(\mathrm{n}=8)$; panjang tubuh 2,00-2,80 mm; lebar kepala 0,40-0,50 mm; panjang alitrunk 0,050,07 mm (Gambar 2, L).

Crematogaster

(Orthocrema)

longipilosa Forel, 1907. Deskripsi dari jenis ini adalah memiliki 3 segmental club; tidak memiliki frontal carinae dan lobe; mandibula lebar dengan tipe triangularis; kepala berbentuk bulat; mata besar terletak di bagian piggir tengah kepala; sisi dorsal pronotum dan mesonotum cembung dengan adanya bulu-bulu halus; propodeum memilki duri; gaster oval memanjang dengan bagian terakhir segmen yang meruncing di ujungnya; tubuh berwarna coklat kekuningan. Pengukuran parameter tubuh $(\mathrm{n}=8)$; panjang tubuh 1,90-3,20 mm; lebar kepala 0,50-0,70 $\mathrm{mm}$; panjang alitrunk 0,05-0,08 $\mathrm{mm}$ (Gambar $2, \mathrm{M})$. 
Jurnal Biologi Universitas Andalas (J. Bio. UA.)

4(4) - Desember 2015: 248-257 (ISSN : 2303-2162)

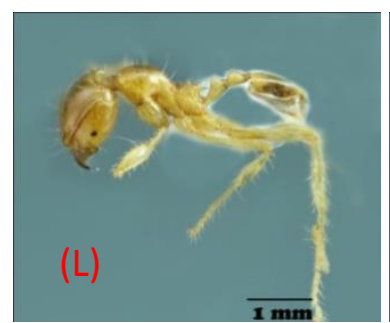

(A)

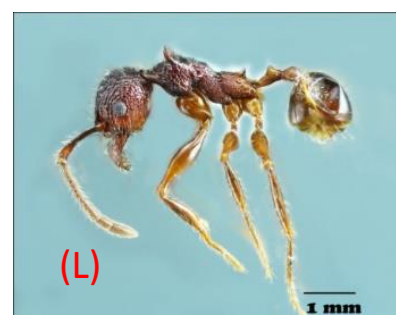

(C)
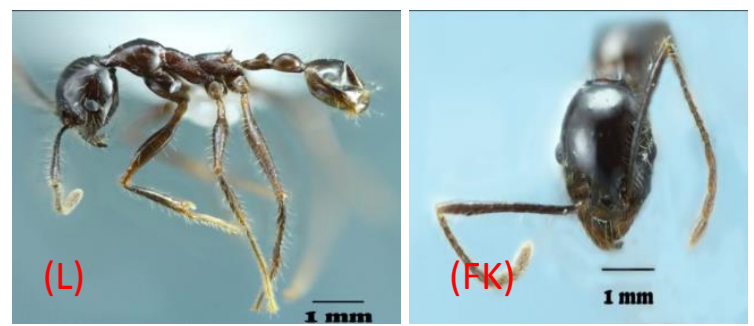

(E)
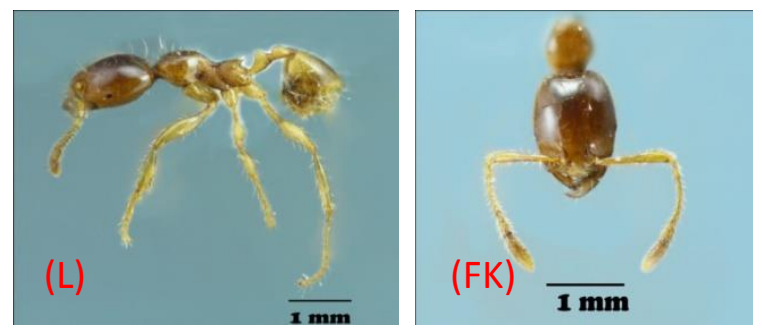

(G)
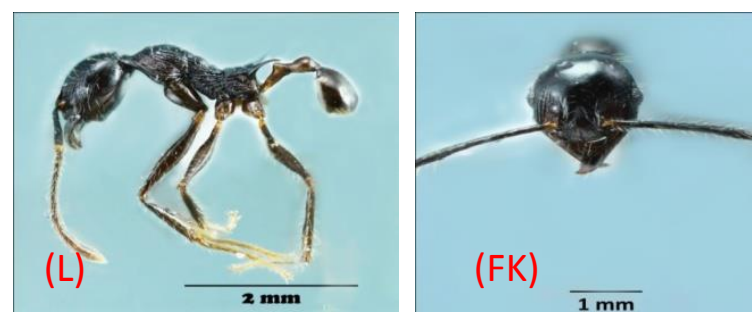

(I)
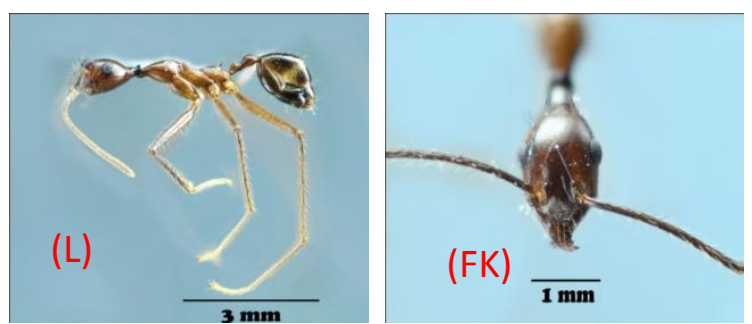

(B)
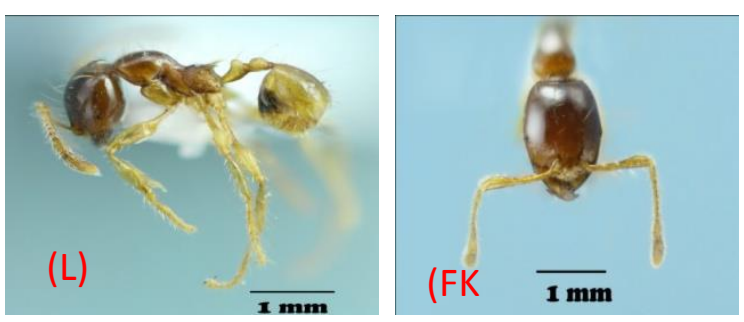

(D)
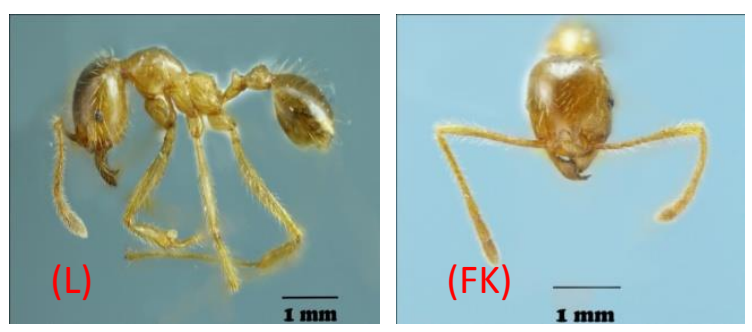

(F)
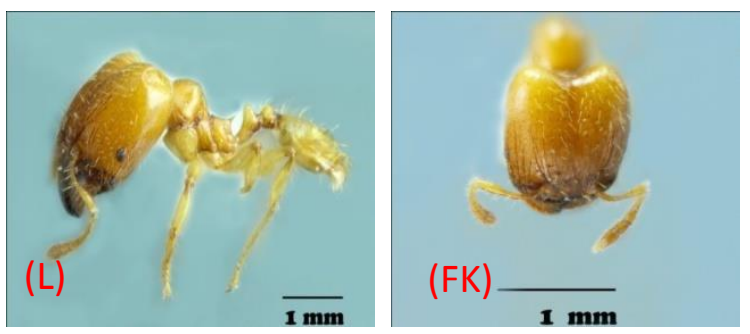

(H)
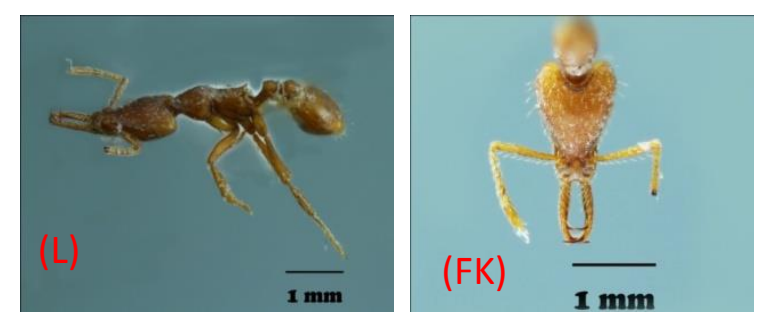

(J)

Gambar 1. Semut subfamily Myrmicinae yang ditemukan di Suaka Alam Maninjau Utara Selatan, Kab. Agam, Sumatera Barat. Sisi lateral (L) dan frontal kepala (FK): (A) Pheidole aristoteles Forel, 1911, (B) Pheidole longipes (Latreille, 1802), (C) Pheidole quadrensis (Forel, 1900), (D) Pheidole sp. 1 of HH, (E) Pheidole sp. 3 of HH, (F) Pheidole sp. 12 of HH, (G) Pheidole sp. 5 of HH, (H) Pheidole sp. 17 of HH, (I) Pheidole sp.18of HH, (J) Strumygenis sp. 2 of HH. 
Jurnal Biologi Universitas Andalas (J. Bio. UA.)

4(4) - Desember 2015: 248-257 (ISSN : 2303-2162)

(Lanjutan Gambar 1.)

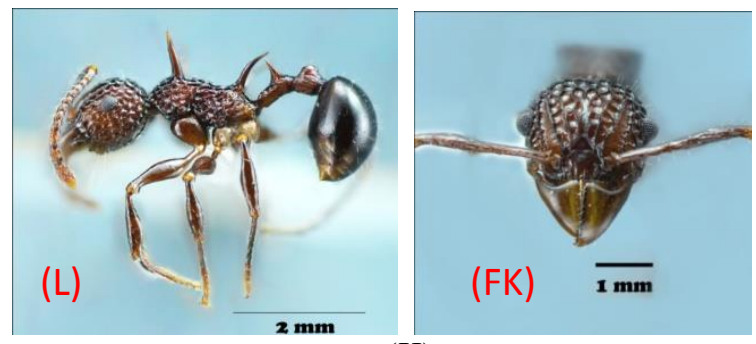

(K)
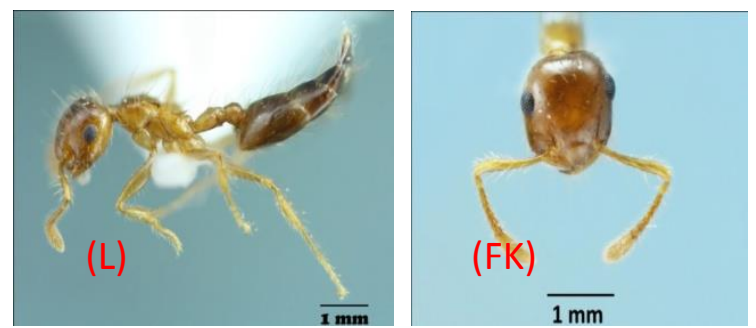

(M)

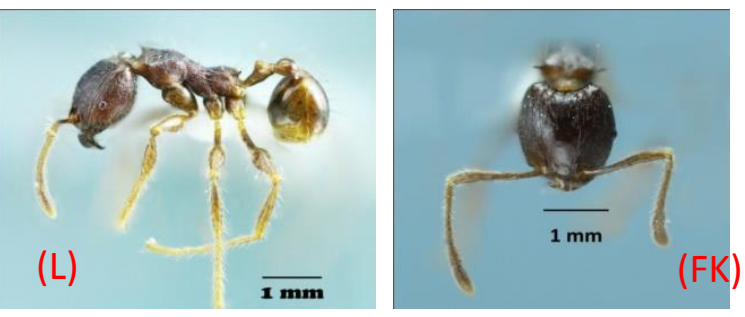

(O)

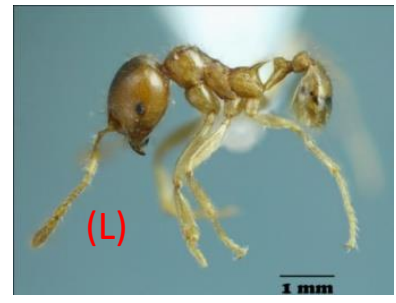

(Q)
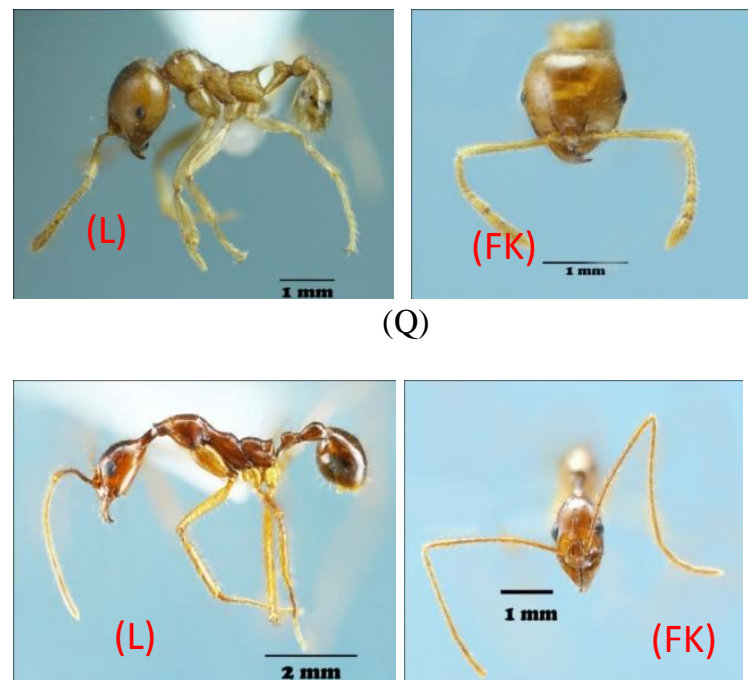

(S)
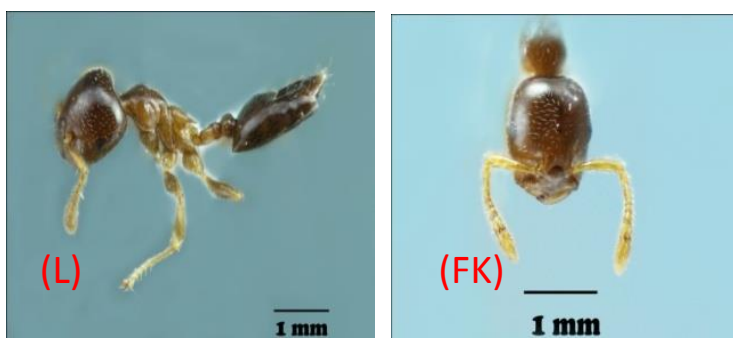

(L)
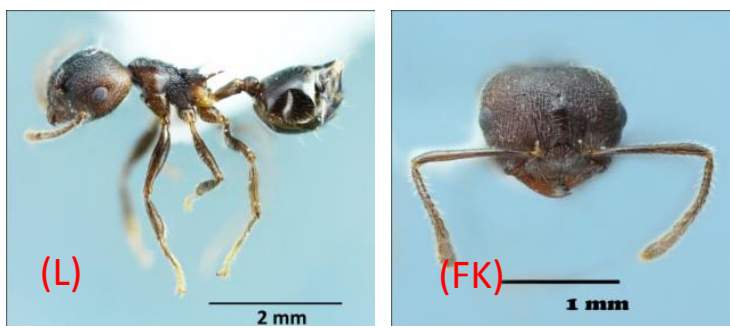

(N)
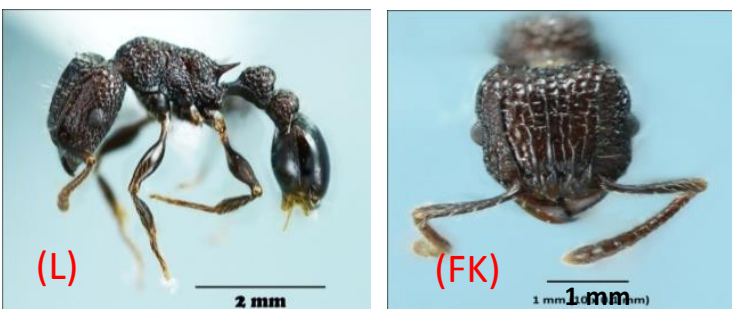

(P)
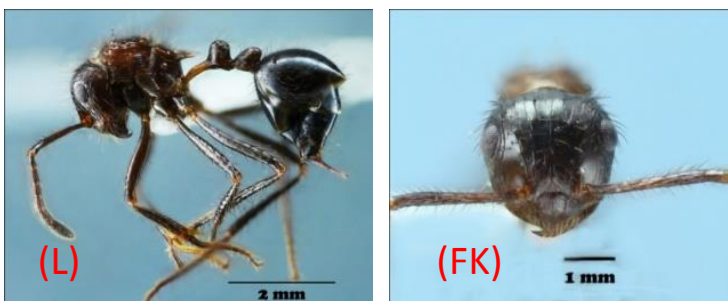

(R)

(K) Acanthomyrmex ferox Emery, 1893, (L) Crematogaster (Decacrema) borneensis Andre, 1896, (M) Crematogaster (Orthocrema) longipilosa Forel, 1907, (N) Crematogaster (Paracrema) modigliani Emery, 1990, (O) Pheidogleton sileneus Smith, 1858, (P) Tetramorium pacificum Mayr, 1870, (Q) Lophomyrmex bedoti Emery, 1893, (R) Myrmicaria sp. of HH, (S) Aphaenogaster (Deromyrma) cf. feae Emery, 1889. 


\section{Crematogaster}

(Paracrema) modigliani Emery, 1990. Deskripsi dari jenis ini adalah mandibula berbentuk triangularis; memiliki antennal socket; antennal scrobe tidak jelas terlihat; pronotum dan mesonotum cembung dari sisi dorsal; propodeum memiliki duri; petiole dengan dua nodus yang terlihat jelas dimana pospetiole berada di permukaan atas gaster; gaster membesar pada segmen pertama dan mengecil pada segmen selanjutnya; tubuh ditutupi oleh bulu-bulu halus; tubuh berwarna coklat kehitaman. Pengukuran parameter tubuh $(\mathrm{n}=10)$; panjang tubuh 3,00-4,30 mm; lebar kepala 0,90-1,00 $\mathrm{mm}$; panjang alitrunk 1,00-1,20 mm (Gambar $2, \mathrm{~N})$.

Tribe Pheidolini, Genus Pheidogleton Mayr, 1862. Karakteristik dari genus Pheidogleton adalah antenna pendek terdiri dari 11 segmen; clypeus halus tanpa ada daerah longitudinal; memiliki sepasang duri yang menyerupai tanduk pada pronatum dan propodeum; permukaan ventral petiole dan postpetiole tanpa ada bagian yang lunak; pekerja memiliki banyak ukuran yang berbeda-beda (Bolton, 1994) dan (Hashimoto, 2003).

Pheidogleton sileneus (Smith, 1858). Deskripsi dari jenis ini adalah kepala berbentuk bulat lonjong; terdapat celah pada bagian anterior kepala; mata kecil terletak dibagian pinggir tengah kepala; antenna terdiri dari 10 segmen; tipe mandibula triangularis; pronotum dan propodeum memiliki sepasang duri yang pendek; mempunyai dua nodus petiole; kepala berwarna hitam; thorak dan gaster berwarna coklat dan hitam dan permukaannya ditutupi oleh bulu-bulu halus. Pengukuran parameter tubuh $(\mathrm{n}=10)$; panjang tubuh $2,90-3,00 \mathrm{~mm}$; lebar kepala 0,50-0,70 mm; panjang alitrunk 0,90-1,00 mm (Gambar 2, O).

Genus Tetramorium Mayr, 1855. Karakteristik dari genus Tetramorium adalah antenna terdiri dari 11-12 segmen dengan 3 segmental club; memiliki antennal scrobe; mata majemuk terletak di bagian tengah kepala; mandibula berbentuk triangularis; propodeum memiliki sepasang duri; petiole mempunyai dua nodus (Hashimoto, 2003).

Tetramorium pacificum Mayr, 1870. Deskripsi dari jenis ini adalah antenna terdiri dari 12 segmen; mandibula berbentuk triangularis; terdapat sepasang duri pendek pada propodeum; permukaan kepala dan thorak agak kasar dan ditutupi oleh bulu-bulu halus; permukaan gaster licin dan ditutupi oleh bulu-bulu halus; memiliki dua nodus petiole; kepala dan thorak berwarna hitam; gaster berwarna coklat dan hitam. Pengukuran parameter tubuh $(\mathrm{n}=1)$; panjang tubuh 4,40 $\mathrm{mm}$; lebar kepala $1,00 \mathrm{~mm}$; panjang alitrunk 1,20 mm (Gambar 2, P).

Genus Lophomyrmex Emery 1892. Karakteristik dari genus Lophomyrmex adalah antenna terdiri dari 12 segmen; tiga segmen antenna berukuran lebih besar; pada thorax, segmen pertama merupakan tuberkulum berduri; bentuk pronatum tinggi seperti busur; postpetiole dekat dengan pusat anterior pada segmen pertama gastral (Hashimoto, 2003).

Lophomyrmex bedoti Emery, 1893. Deskripsi dari jenis ini adalah kepala berbentuk bulat; mata terletak di bagian tengah pinggir kepala; tipe mandibula triangularis; sisi dorsal dari pronotum cembung; sisi dorsal mesonatum cekung; sisi dorsal propodeum cembung serta memiliki sepasang duri; permukaan kepala dan gaster licin serta ditutupi oleh rambut-rambut halus; tubuh memiliki warna kuning kecoklatan. Pengukuran parameter tubuh $(\mathrm{n}=10)$; panjang tubuh 1,50-2,40 mm; lebar kepala 0,50-0,80 $\mathrm{mm}$; panjang alitrunk $0,50-0,80 \mathrm{~mm}$ (Gambar 2, Q).

Tribe Solenopsidini, Genus Myrmicaria Saunders, 1842. Karakteristik dari genus Myrmicaria adalah antenna terdiri dari 7 segmen termasuk 3 segmental club; terdapat sepasang duri pada propodeum; peduncle pada petiole panjang; mata besar dan seluruh tubuh ditutupi oleh bulu-bulu yang jarang (Hashimoto, 2003).

Myrmicaria sp. of HH. Deskripsi dari jenis ini adalah antenna terdiri dari 7 segmen termasuk 3 segmental club; mata besar 
terletak di bagian tengah pinggir kepala; mandibula berbentuk triangularis; protothorak menyatu (thorak dan kepala terlihat menyatu); sisi dorsal dari pronotum dan mesonotum cembung dengan pola yang bergerigi; sisi dorsal propodeum cembung dengan sepasang duri; peduncle panjang; kepala, thorak, kaki, petiole dan gaster ditutupi oleh bulu-bulu halus yang banyak; gaster memiliki sting; tubuh berwarna coklat kehitaman. Pengukuran parameter tubuh $(\mathrm{n}=10)$; panjang tubuh 5,00-6,00 mm; lebar kepala 1,00-1,50 mm; panjang alitrunk 1,501,90 mm (Gambar 2, R).

Tribe Stenammini, Genus Aphaenogaster Mayr, 1853. Karakteristik dari genus Aphaenogaster adalah memiliki jumlah antenna 12 segmen dengan 4 segmental club; permukaan atas kepala memiliki antennal scrobe; bagian mesonotum dan propodeum seperti tertekan sehingga bagian mesosoma tidak sejajar; memiliki dua nodus petiole yang terlihat jelas; mandibula berbentuk triangularis; pada leher terdapat cincin. (Bolton, 1994) dan (Hashimoto, 2003).

Aphaenogaster (Deromyrma) cf. feae Emery, 1889. Deskripsi dari jenis ini adalah kepala berbentuk bulat; mata besar terletak di bagian pinggir tengah kepala; antenna terdiri dari 12 segmen termasuk 4 segmental club; memiliki antennal socket; mandibula berbentuk triangularis; mesosoma memanjang dan ramping; scape lebih panjang daripada kepala; sisi dorsal pronotum lebih cembung dibandingkan dengan sisi dorsal mesonotum dan propodeum; propodeum memiliki bagain yang meruncing seperti duri; petiole dan postpetiole terlihat dengan jelas; kepala, mesosoma, petiole dan gaster ditutupi oleh bulu-bulu halus dan memiliki permukaan tubuh yang licin; kepala, mesosoma, kaki, petiole dan gaster berwarna kuning kecoklatan. Pengukuran parameter tubuh $(\mathrm{n}=3)$; panjang tubuh $5,00 \mathrm{~mm}$; lebar kepala $0,80 \mathrm{~mm}$; panjang alitrunk 1,90-2,00 mm (Gambar 2, S).

\section{Kesimpulan}

Dari penelitian yang telah dilakukan mengenai semut dari subfamily Myrmicinae di Kawasan Suaka Alam Maninjau Utara Selatan, Kabupaten Agam, Sumatera Barat didapatkan 19 jenis yang tergolong ke dalam 9 genus dan 5 tribe. Semut yang dominan didapatkan adalah genus Pheidole (9 jenis), diikuti oleh genus Crematogaster (9 jenis).

\section{Ucapan Terimakasih}

Ucapan terimakasih disampaikan kepada Rijal Satria M.Sc (Tokyo Metropolitan, University) dan Diyona Putri M.Si yang telah membantu dalam identifikasi sampel semut. Bapak Prof. Dr. Dahelmi, Zuhri Syam, M.P dan Ibu Dr. Resti Rahayu atas masukan dan saran dalam penulisan dan BKSDA Sumatera Barat. Penelitian ini didanai oleh pendanaan Hibah Kerjasama Luar Negeri DIKTI 2015 (SK NO: 09/H.16/KLN-PI/LPPM/2015) dengan ketua Dr. Henny Herwina.

\section{Daftar Pustaka}

Agosti, D., J.D. Majer, L. E. Alonso and T.R. Schultz. 2000. Ants Standard Methods For Measuring and Monitoring Biodiversity. Smithonian Institutio Press. Washington, U. S. A.

BKSDA Sumatera Barat. 2007. Buku Informasi Kawasan Konservasi. BKSDA Sumatera Barat.

Bolton, B.O.1994. Identification guide to the ant genera of the world. Harvard University Press, Cambridge, MA. $222 \mathrm{pp}$.

Borror, J.D., A.C. Triplehorn and F.N. Johnson. 2005. Pengenalan Pelajaran Serangga, Edisi ketujuh. Gadjah Mada University Press.Yogyakarta.

Eguchi, K. 2000. Two New Pheidole Species With A-5 segmented Antennal Club (Hymenoptera: Formicidae). Entomological Science 3 (4): 687692.

Eguchi, K. 2001. A Revision of Borneoan Species of the Ants Genus Pheidole 
(Insecta: Hymenoptera: Formicidae: Myrmicinae. Tropics, Monograpics No. 2 ISSN 0917: 415X.

Folgarait, P.J. 1998. Ant Biodiversity And Its Relationship To Ecosystem Functioning: A Review. Biodiversity and Conservation 7: 1221-1244.

Hansen, L and A. Art. 2011. Identification and Habits of Key Ant Pests in the Pacific Northwest. A Pacific Northwest Extension Publication: Washington State University. http://cru.cahe.wsu.edu/CEPublicatio ns/PNW624/PNW624.pdf. Diakses tanggal 22 Februari 2015.

Hashimoto, Y., S. Yamane and M. Mohamed. 2001. How to design an inventory method for ground-level ants in tropical forest. Nature and Human Activities 6: 25-30.

Hashimoto,Y. 2003. Identification Guide To The Ant Genera of Borneo In: Hashimoto, Y., R, Homathevi (ed.), Inventory and Collection Total protocol For Understanding of Biodiversity. Reseach and Education Component BBEC Programme.

Hilmi, L., H. Herwina dan Dahelmi. 2015. Semut Subfamily Myrmicinae di Cagar Alam Rimbo Panti, Kabupaten Pasaman, Sumatera Barat. Jurnal Natural Science 4 (2): 1-9.

Jaitrong, W. 2011. Identification Guide to the Ant Genera of Thailand. Thailand National Science Museum Press. PathumThani. 1-115pp.
Kaspari, M. 2000. A Primer on Ant Ecology. In: Agosti D, Majer JD, Alonso LE, Schultz TR (ed.), Ants: Standard Methods for Measuring and Monitoring Biodiversity. Washington: Smithsonian Institution Press Pr.p 924.

Munawaroh, E. 2009. Eksplorasi Keanekaragaman Tumbuhan Di Kawasan Suaka Alam Maninjau UtaraSelatan. Kab. Agam, Prop. Sumatera Barat. Seminar Nasional Biologi XX dan Kongres PBl XIV UIN Maliki Malang.

Schultz, T.R and T.P. McGlynn. 2000. The Interctions of Ants with other Organism. In: Agosti D, Majer JD, Alonso LE, Schultz TR (ed.), Ants: Standard Methods for Measuring and Monitoring Biodiversity. Washington: Smithsonian Institution Press Pr.p 3544.

Wilson, E.O. 2005. Pheidole in the New World: A Dominant, Hyperdiverse Ant Genus. Rev. Biol. Trop. (Int. J. Trop. Biol. 53 (1-2): 297-304. 